\title{
Balloon-catheter-assisted endoscopic snare resection for choledochocele using a single-channel duodenoscope
}

Choledochocele, or type III choledochal cyst in Todani's classification, is a rare congenital disease [1-3]. Pancreatobiliary symptoms and the risk of malignancy are the reasons for treatment, which is usually done by surgical excision or, in some cases, by endoscopic resection [2-5].

A 75-year-old man with abdominal pain, jaundice, occasional fever, elevated canalicular enzymes, conjugated bilirubin $(1.3 \mathrm{mg} / \mathrm{dL}$, normal range $0.1-0.4 \mathrm{mg} / \mathrm{dL})$ and cholelithiasis, and choledocholithiasis with common bile duct dilatation as seen on ultrasonography and CT scan, underwent endoscopic retrograde cholangiopancreatography (ERCP), which also revealed a choledochocele ( $\mathbf{F i g} \mathbf{1}$ ). The patient refused surgery and a ballooncatheter-assisted endoscopic snare resection with a single-channel therapeutic duodenoscope was performed.

After catheterization of the common bile duct with a guide wire, a balloon catheter was passed through the loop of a $20-\mathrm{mm}$ diameter snare which wrapped around the wire and was then inserted deeply into the choledochocele ( Fig. 2). The insufflated balloon was pulled back toward the duodenal lumen and the snare grasped close to the base of the choledochocele, and the marsupialization was completed ( $\bullet$ Fig. 3). After this, sphincterotomy was performed and stones removed.

The cyst had duodenal mucosa externally and choledochal mucosa internally with no atypical changes. A laparoscopic cholecystectomy was done and the patient remains without symptoms and with normal findings on endoscopic follow-up after 1 year ( $\bullet$ Fig. 4 ).

The risk of biliary duct perforation during surgical resection is well known; however, because endoscopic resection is a new method, the risk it presents is as yet unknown; more studies are needed on this subject. The technique employed here has been described before using a double-channel duodenoscope, and this is easier because it is not necessary to manage the accessories outside of the duodenoscope before introducing the whole system into the channel [5]. How-

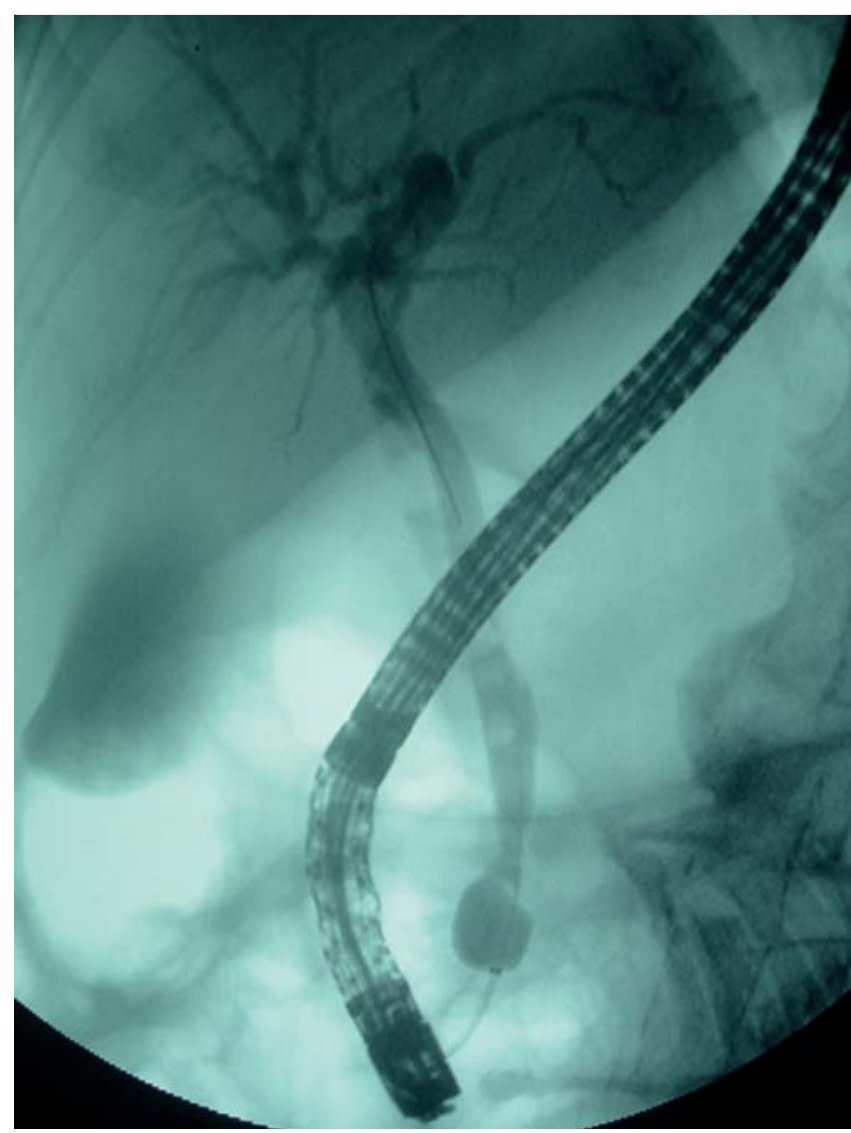

Fig. 1 Endoscopic retrograde cholangiopancreatography showing the choledochocele.
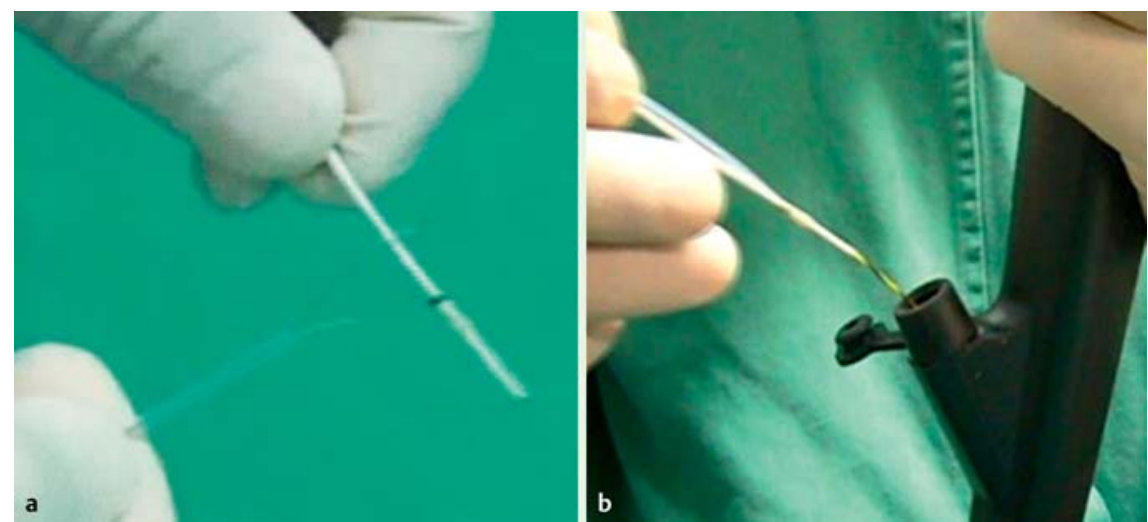

Fig. 2 Snare wrapped around the balloon to fit in a single-channel duodenoscope.

ever, since a double-channel duodenoscope is not available in all hospitals, the present case report shows that the single-channel technique can be performed with the same results and is also an innovative and minimally invasive technique for the treatment of symptomatic choledochocele.

Endoscopy_UCTN_Code_TTT_1AR_2AF

Competing interests: None 

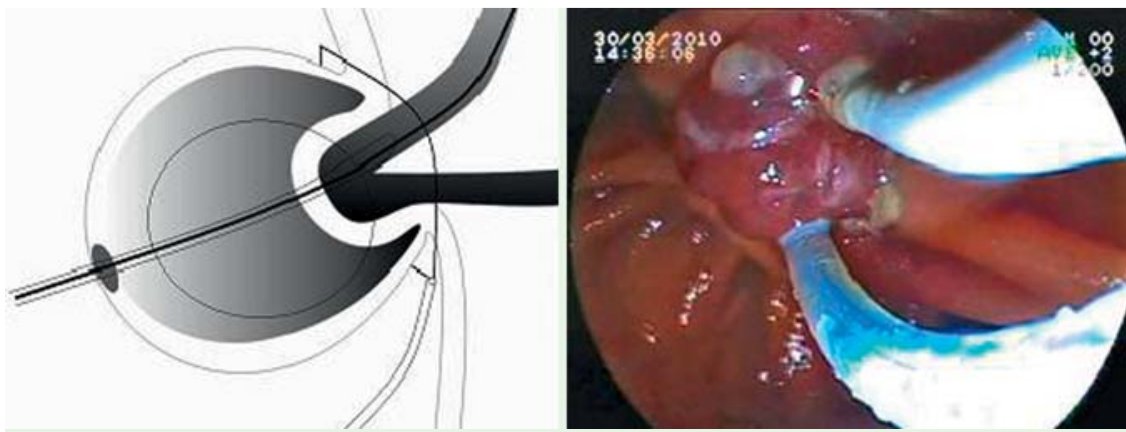

Fig. 3 Balloon-catheter-assisted endoscopy snare resection technique: schematic diagram and endoscopic image.

J. Hiratsuka, T. Akiba, M. Kucera Kesties, P. Brant, L. Costa Almeida

Endoscopy Department, Santa Casa de São Paulo, São Paulo, Brazil

\section{References}

1 Singham J, Yoshida EM, Scudamore CH. Choledochal cysts. Part 1 of 3: Classification and pathogenesis. Can J Surg 2009; 52: $434-440$

2 Chatila R, Andersen DK, Topazian M. Endoscopic resection of a choledochocele. Gastrointest Endosc 1999; 50: 578-580

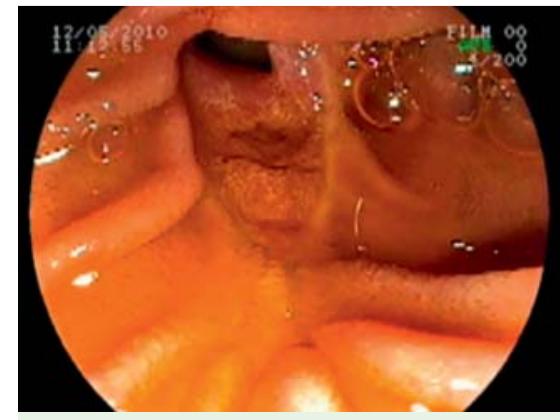

Fig. 4 Follow-up 1 year after endoscopic resection.

Bibliography

DOI $10.1055 / \mathrm{s}-0030-1257030$

Endoscopy 2012; 44: E6-E7

(c) Georg Thieme Verlag KG Stuttgart · New York . ISSN 0013-726X

\section{Corresponding author}

\section{J. Hiratsuka, MD}

Endoscopy Department, Santa Casa de São Paulo Rua Marquês de Itu, no 382 ap 73 - Vila Buarque São Paulo

CEP 01223-000

Brazil

jhiratsuka@uol.com.br 